\title{
Abortion-Related Mortality in the United States 1998-2010
}

\author{
Suzanne Zane, DVM, MPH, Andreea A. Creanga, MD, PhD, Cynthia J. Berg, MD, MPH, \\ Karen Pazol, PhD, MPH, Danielle B. Suchdev, MPH, Denise J. Jamieson, MD, MPH, and \\ William M. Callaghan, MD, MPH \\ Division of Reproductive Health, National Center for Chronic Disease Prevention and Health \\ Promotion, Centers for Disease Control and Prevention, Atlanta, Georgia
}

\begin{abstract}
OBJECTIVE-To examine characteristics and causes of legal induced abortion-related deaths in the United States between 1998 and 2010.

METHODS-Abortion-related deaths were identified through the national Pregnancy Mortality Surveillance System with enhanced case-finding. We calculated the abortion mortality rate by race, maternal age, and gestational age and the distribution of causes of death by gestational age and procedure.
\end{abstract}

RESULTS-During the period from 1998-2010, of approximately 16.1 million abortion procedures, 108 women died, for a mortality rate of 0.7 deaths per 100,000 procedures overall, 0.4 deaths for non-Hispanic white women, 0.5 deaths for Hispanic women, and 1.1 deaths for black women. The mortality rate increased with gestational age, from 0.3 to 6.7 deaths for procedures performed at 8 weeks or less and at 18 weeks or greater, respectively. A majority of abortionrelated deaths at 13 weeks of gestation or less were associated with anesthesia complications and infection, whereas a majority of abortion-related deaths at more than 13 weeks of gestation were associated with infection and hemorrhage. In 20 of the 108 cases, the abortion was performed as a result of a severe medical condition where continuation of the pregnancy threatened the woman's life.

CONCLUSION—Deaths associated with legal induced abortion continue to be rare events-less than 1 per 100,000 procedures. Primary prevention of unintended pregnancy, including those in women with serious pre-existing medical conditions, and increased access to abortion services at early gestational ages may help to further decrease abortion-related mortality in the United States.

Over the past 35 years, approximately half of pregnancies in the United States were unintended. Of these, about $40 \%$ were terminated by induced abortion, ${ }^{1,2}$ with an estimated 1.1 million legal induced abortions performed in the United States in $2011 .{ }^{3}$ Since its legalization in 1973, the mortality rate from legal induced abortion has remained very low, at about 1 abortion-related death per 100,000 abortion procedures (Fig. 1). ${ }^{4}$ Changes in the

Corresponding author: Suzanne Zane, DVM, MPH, Division of Reproductive Health, National Center for Chronic Disease Prevention and Health Promotion, Centers for Disease Control and Prevention (CDC), 4770 Buford Hwy, NE, Mail Stop F-74, Atlanta, GA 30341-3717; saz3@cdc.gov.

Financial Disclosure

The authors did not report any potential conflicts of interest. 
population of women of reproductive age as well as changes in abortion techniques and methods, such as the approval in 2000 of mifepristone for early medical abortion, may potentially affect mortality from abortion.

The Division of Reproductive Health at the Centers for Disease Control and Prevention (CDC) has done national epidemiologic surveillance of mortality associated with legal induced abortion since 1972. ${ }^{5}$ All potential deaths from abortion receive in-depth investigation: abortion mortality rates are reported annually in the CDC's Abortion Surveillance Reports, ${ }^{4}$ and more comprehensive analyses are published periodically in peerreviewed publications that cover the years $1972-1997 .{ }^{6-8}$ To provide the most recent, complete information on deaths related to legal induced abortion, this article summarizes key epidemiologic and clinical information on these deaths in the United States between 1998 and 2010.

\section{MATERIALS AND METHODS}

The first source of potential cases of deaths related to induced abortion is the CDC Pregnancy Mortality Surveillance System. This system mainly relies on vital records (ie, death certificates and matching live birth or fetal death certificates, if available) received from all 50 states, Washington, DC, and New York City. ${ }^{9}$ During review of these pregnancy-associated deaths (ie, deaths during or within 1 year of pregnancy), CDC epidemiologists identify all deaths potentially associated with induced abortion. Additional methods used to identify other potential abortion-related deaths include media reports, such as computerized searches of Lexis Nexis, and reports by public health agencies, state-based maternal mortality review committees, professional organizations, health care providers, and individuals.

For all potential abortion-related deaths, medical records and autopsy reports are requested and an in-depth investigation conducted. Two clinically trained CDC epidemiologists separately review the data, reach consensus on the cause of death, abortion type (legal induced, illegal induced, spontaneous, or unknown), and gestational age. In cases with adequate medical documentation, they assess whether the woman had a severe medical condition where continuing the pregnancy threatened her life, such as pulmonary hypertension; severe or end-stage renal or hepatic disease; or major hematologic, autoimmune, or metabolic conditions, or whether the abortion was done in an attempt to save her life. Data then are abstracted using standardized case summary forms.

An abortion is defined as legal if it is performed by a licensed clinician and as illegal if performed by any other person. ${ }^{4}$ An abortion-related death is defined as a death resulting from a direct complication of an induced abortion, an indirect complication caused by a chain of events initiated by an abortion procedure, or the aggravation of a pre-existing condition by the physiologic or psychological effects of the abortion. ${ }^{4}$ All deaths determined to be causally related to induced abortion are classified as abortion-related regardless of the time between the abortion and death. ${ }^{4}$ In addition, any pregnancy-related death (ie, deaths causally related to pregnancy) in which the pregnancy outcome is induced abortion is considered an abortion-related death regardless of the causal relation between the abortion 
procedure itself and death. ${ }^{4}$ Finally, if the death occurs from an unrecognized ectopic pregnancy after a legal induced abortion for presumed intrauterine pregnancy, the case is considered abortion-related.

The type of abortion procedure was categorized as: 1) no procedure if Laminaria were placed or anesthesia was performed but the planned abortion procedure never occurred; 2) medical procedure if medication(s), but no surgical instruments, were used to induce an abortion; at 8 weeks of gestation or less, this procedure typically entailed administration of mifepristone followed by misoprostol; at more than 8 weeks of gestation, it typically entailed the administration of vaginal prostaglandins; 3 ) suction curettage (formerly dilation and curettage) for surgical abortion at 13 weeks of gestation or less; 4) dilation and evacuation for surgical abortion at more than 13 weeks of gestation; 5) other procedure (ie, intrauterine instillation other surgical procedure); and 6) unknown procedure. Causes of death were categorized per the Pregnancy Mortality Surveillance System as hemorrhage, infection, embolism (thrombotic and amniotic), anesthesia complications, cardiovascular conditions, and other noncardiovascular medical conditions, such as pulmonary, collagen vascular, renal, and hematologic conditions. ${ }^{10}$ Other variables were categorized as follows: gestational age at the time of the procedure ( 8 or less, $9-13,14-17,18$ or more completed weeks of gestation), age (19 years or younger, 20-24, 25-29, 30-34, 35 years or older), race (white, black, other); Hispanic origin (yes, no, unknown), nativity (U.S.- or foreign-born), gravidity (1, 2, 3 or more, unknown), number of previous live births $(0,1,2,3$ or more, unknown), education (11th grade or less, 12th grade, more than 12th grade, unknown), and marital status (never married, married or cohabiting, divorced or widowed, unknown).

Data for the denominator (ie, annual numbers of legal induced abortions in the United States) were from the Guttmacher Institute (Table 1) ${ }^{3}$; we applied the gestational age distribution from the CDC's Abortion Surveillance System to obtain the number of abortion procedures by gestational age category. ${ }^{4}$ Information on gestational age at the time of procedure was missing for six cases. Assignment of gestational age to these cases is described in Scenario 5 in Table 2. To estimate the distribution of abortion procedures by race-Hispanic ethnicity and maternal age, we used data from the 2000 and 2008 Guttmacher Institute Abortion Patient Surveys. ${ }^{11,12}$ The distribution of abortion procedures for these two variables in the two surveys was essentially identical, and we used the mean distribution to calculate the number of abortion procedures by race-ethnicity and maternal age. For other variables of potential interest, there was not sufficient information either for the cases or the number of procedures to allow calculation of mortality rates. For these variables, we tabulated the distribution of the characteristics among the women with abortion-related deaths.

The abortion mortality rate, defined as the number of abortion-related deaths per 100,000 abortion procedures, was calculated for the study period 1998-2010 by race and Hispanic ethnicity, maternal age, and gestational age category. We tabulated the distribution of causes of death by gestational age and type of abortion procedure. All analyses were performed in Stata 12. Surveillance and research activities summarized in this report were deemed exempt from review by the CDC's institutional review board. 


\section{RESULTS}

Between 1998 and 2010, among approximately 16.1 million abortion procedures in the United States, there were 108 legal induced abortion-related deaths, yielding an abortion mortality rate of 0.7 deaths per 100,000 legal induced abortion procedures; the mortality rate was 0.4 for non-Hispanic white women, 0.5 for Hispanic women, 1.1 for black women, and 0.7 for women of other races. The mortality rates by maternal age were $0.04,0.6,0.6,1.1$, and 0.9 for women 19 years and younger, 20-24, 25-29, 30-34 and 35 years or older, respectively. The annual number of deaths ranged between four deaths in 1999 and 12 deaths in 2008 , for an annual mortality rate between 0.3 and 1.0 per 100,000 procedures. ${ }^{4}$ Of the 108 abortion-related deaths, 28 followed procedures performed at 8 weeks of gestation or less, 23 between 9 and 13 weeks, 21 between 14 and 17 weeks, and 36 at 18 weeks or greater (Table 3). Abortion mortality rates increased with gestational age, from 0.3 deaths per 100,000 procedures performed at 8 weeks of gestation or less to 6.7 deaths per 100,000 procedures performed at 18 weeks of gestation or greater (Fig. 2). The distribution of deaths from abortion-related causes by key sociodemographic characteristics is shown in Table 3 .

Of the 48 women who died after undergoing abortion at 13 weeks of gestation or less, 28 had undergone surgical abortion and 12 had undergone a medical abortion procedure (Table 4). The most common cause of death after a surgical abortion at 13 weeks of gestation or less was anesthesia complications (13 deaths); after medical abortion at 13 weeks of gestation or less, the most common cause of death was infection ( 9 deaths). Of the 54 women who died after undergoing abortion at more than 13 weeks, 39 had undergone surgical abortion and eight had undergone a medical abortion procedure. The most common causes of death after a second-trimester surgical abortion were hemorrhage (16 deaths) and infection (12 deaths).

Nine of the 20 deaths after medical abortion were caused by infection with Clostridium species; seven of these women had confirmed infection with Clostridium sordellii after using mifepristone-misoprostol at 4-7 weeks of gestation, and two had confirmed infection with Clostridium perfringens, one after using mifepristone with misoprostol at 8 weeks of gestation and one after use of Laminaria and misoprostol at 19 weeks of gestation. Among the deaths attributable to anesthesia, the methods used varied from local only to combined local and intramuscular-intravenous sedation to general anesthesia. Overall, 20 abortionrelated deaths (19\%) occurred among women with severe medical conditions where continuing the pregnancy threatened the life of the woman. The vast majority of these conditions existed before the pregnancy.

\section{DISCUSSION}

In the United States during the period from 1998-2010, an average of eight abortion-related deaths were identified each year, for an abortion mortality rate of 0.7 per 100,000 legal induced abortion procedures, the rate being 0.4 for non-Hispanic white women, 0.5 for Hispanic women, and 1.1 for black women. The mortality rate increased with increasing age, from 0.4 for women 19 years and younger to 1.1 for women 30-34 and 0.9 for women

Obstet Gynecol. Author manuscript; available in PMC 2016 August 01. 
35 years and older. The abortion mortality rate has been stable for the past 3 decades (Fig. 1) and is in line with corresponding rates in other developed countries. ${ }^{13}$

The most frequent causes of death were infection and anesthesia complications after medical and surgical abortions, respectively, at 13 weeks of gestation or less, and hemorrhage and infection after abortions at more than 13 weeks. Gestational age at the time of the abortion remains the strongest risk factor for abortion-related mortality. ${ }^{8}$ Abortion-related deaths are clinically and statistically rare events, and the risk of death after an abortion at 8 weeks of gestation or less is 0.3 per 100,000 or 3 per million procedures. However, even at 18 weeks or later, the risk of mortality was low, 6.7 deaths per 100,000 procedures. Ways to facilitate access to abortion services at lower-risk, early gestational ages warrant further examination.

Black women have a risk of abortion-related death that is three times greater than that for white women. This is similar to the black:white risk ratio for all pregnancy outcomes of 3.2. ${ }^{9,14}$ The reason for this remains unclear; abortion surveillance data from 29 states (which exclude California, Florida, Illinois, and Mississippi) suggest that black women, compared with non-Hispanic white women, are only slightly less likely to obtain abortions in the first trimester-90\% compared with $93 \% .^{4}$

This is the first analysis of abortion-related mortality surveillance data after U.S. Food and Drug Administration (FDA) approval in 2000 of mifepristone for early medical abortion. Mifepristone has become an integral part of abortion provision in the United States and contributed to the trend toward very early abortions. ${ }^{15,16}$ Of note are eight deaths due to Clostridium species infection after early medical abortions using mifepristone with misoprostol. Clinical details on these deaths have been reported previously after in-depth investigations by the FDA and CDC. ${ }^{17-20}$

Additionally, this analysis includes information on the number of women whose abortions were done in an attempt to save their lives, comprising almost $20 \%$ of all the abortion deaths in this time period. All but one of these 20 deaths were due to serious pre-existing medical conditions exacerbated by pregnancy, such as pulmonary hypertension and end-stage renal disease. Counseling such women about the very real risks of pregnancy and the provision of the most effective methods of contraception should be part of their ongoing care.

This study is not without limitations. Reporting of pregnancy-associated deaths by states to the Pregnancy Mortality Surveillance System may be incomplete. However, the CDC uses multiple other methods to identify such deaths, and every report of a potential abortionrelated death is followed up and investigated. Moreover, ascertainment of deaths after abortions with mifepristone benefits from the mandatory reporting of possible medicationrelated serious adverse events to Danco Laboratories, the single distributor of mifepristone in the United States, and to the FDA. ${ }^{21}$ Also, important clinical information (eg, gestational age, specific abortion procedure, or cause of death) was not available for a small proportion of abortion-related deaths.

Legal induced abortion remains an extremely safe procedure, with a mortality rate of 0.7 per 100,000 procedures. The published mortality rate for pregnancies ending in a live birth is 8.8 deaths per 100,000 live births. ${ }^{22}$ Improved access to abortion services at lower-risk, early

Obstet Gynecol. Author manuscript; available in PMC 2016 August 01. 
gestational ages will lower abortion mortality even more. Regardless, primary prevention of unintended pregnancy is optimal, especially for women with the most serious medical conditions. As in all areas of medicine, continuous quality improvement in clinical practices should be encouraged and monitoring of trends in procedures and outcomes continued.

\section{Acknowledgments}

The authors thank Carla Syverson and Kristi Seed for their assistance with data entry and review for the Pregnancy Mortality Surveillance System during 1998-2010.

The findings and conclusions in this report are those of the authors and do not necessarily represent the official position of the Centers for Disease Control and Prevention.

\section{REFERENCES}

1. Finer LB, Henshaw SK. Disparities in rates of unintended pregnancy in the United States, 1994 and 2001. Perspect Sex Reprod Health. 2006; 38:90-96. [PubMed: 16772190]

2. Finer LB, Zolna MR. Shifts in intended and unintended pregnancies in the United States, 20012008. Am J Public Health. 2014; 104:S43-S48. [PubMed: 24354819]

3. Jones RK, Jerman J. Abortion incidence and service availability in the United States, 2011. Perspect Sex Reprod Health. 2014; 46:3-14. [PubMed: 24494995]

4. Pazol K, Creanga AA, Burley KD, Jamieson DJ. Centers for Disease Control and Prevention. Abortion surveillance-United States, 2011. MMWR Surveill Summ. 2014; 63:1-41. [PubMed: 25426741]

5. Cates W, Grimes DA, Smith JC, Tyler CW. Legal abortion mortality in the United States: epidemiologic surveillance, 1972-74. JAMA. 1977; 237:452-455. [PubMed: 576267]

6. Atrash HK, MacKay HT, Binkin NJ, Hogue CJ. Legal abortion mortality in the United States: 1972 to 1982. Am J Obstet Gynecol. 1987; 156:605-612. [PubMed: 3826208]

7. Lawson HW, Frye A, Atrash HK, Smith JC, Shulman HB, Ramick M. Abortion mortality, United States, 1972 through 1987. Am J Obstet Gynecol. 1994; 171:1365-1372. [PubMed: 7977548]

8. Bartlett LA, Berg CJ, Shulman HB, Zane SB, Green CA, Whitehead S, et al. Risk factors for legal induced abortion-related mortality in the United States. Obstet Gynecol. 2004; 103:729-737. [PubMed: 15051566]

9. Creanga AA, Berg CJ, Syverson C, Seed K, Bruce FC, Callaghan WM. Pregnancy-related mortality in the United States, 2006-2010. Obstet Gynecol. 2015; 125:5-12. [PubMed: 25560097]

10. Centers for Disease Control and Prevention. [Retrieved November 16, 2014] Pregnancy mortality surveillance in the United States. 2013. Available at: http://www.cdc.gov/reproductivehealth/ MaternalInfantHealth/Pregnancy-relatedMortality.htm

11. Jones RK, Darroch JE, Henshaw SK. Patterns in the socioeconomic characteristics of women obtaining abortions in 2000-2001. Perspect Sex Reprod Health. 2002; 34:226-235. [PubMed: 12392215]

12. Jones RK, Kavanaugh ML. Changes in abortion rates between 2000 and 2008 and lifetime incidence of abortion. Obstet Gynecol. 2011; 117:1358-1366. [PubMed: 21606746]

13. Cantwell R, Clutton-Brock T, Cooper G, Dawson A, Drife J, Garrod D, et al. Saving mothers' lives: reviewing maternal deaths to make motherhood safer: 2006-2008. The Eighth Report of the Confidential Enquiries into Maternal Deaths in the United Kingdom. BJOG. 2011; 118:1-203. [PubMed: 21356004]

14. Creanga AA, Berg CJ, Syverson C, Seed K, Bruce C, Callaghan WM. Race, ethnicity and nativity differentials in pregnancy-related mortality in the United States: 1993-2006. Obstet Gynecol. 2012; 120:261-268. [PubMed: 22825083]

15. Finer LB, Wei J. Effect of mifepristone on abortion access in the United States. Obstet Gynecol. 2009; 114:623-630. [PubMed: 19701044] 
16. Pazol K, Creanga AA, Zane SB. Trends in use of medical abortion in the United States: reanalysis of surveillance data from the centers for disease control and prevention, 2001-2008. Contraception. 2012; 86:746-751. [PubMed: 22770796]

17. Fischer M, Bhatnagar J, Guarner J, Reagan S, Hacker JK, Van Meter SH, et al. Fatal toxic shock syndrome associated with Clostridium sordellii after medical abortion. N Engl J Med. 2005; 353:2352-2360. [PubMed: 16319384]

18. Cohen AL, Bhatnagar J, Reagan S, Zane SB, D’Angeli MA, Fischer M, et al. Toxic shock associated with Clostridium sordellii and Clostridium perfringens after medical and spontaneous abortion. Obstet Gynecol. 2007; 110:1027-1033. [PubMed: 17978116]

19. Meites E, Zane S, Gould G. Fatal Clostridium sordellii infections after medical abortions (correspondence). N Engl J Med. 2010; 363:1382-1383. [PubMed: 20879895]

20. Centers for Disease Control and Prevention. Clostridium sordellii toxic shock syndrome after medical abortion with mifepristone and intravaginal misoprostol—United States and Canada, 2001-2005. MMWR Morb Mortal Wkly Rep. 2005; 54:724. [PubMed: 16049422]

21. Food and Drug Administration. [Retrieved November 9, 2014] Mifeprex risk evaluation and mitigation strategy. Available at: http://www.fda.gov/downloads/Drugs/DrugSafety/

PostmarketDrugSafetyInformationforPatientsandProviders/UCM258412.pdf

22. Raymond EG, Grimes DA. The comparative safety of legal induced abortion and childbirth in the United States. Obstet Gynecol. 2012; 119:215-219. [PubMed: 22270271] 


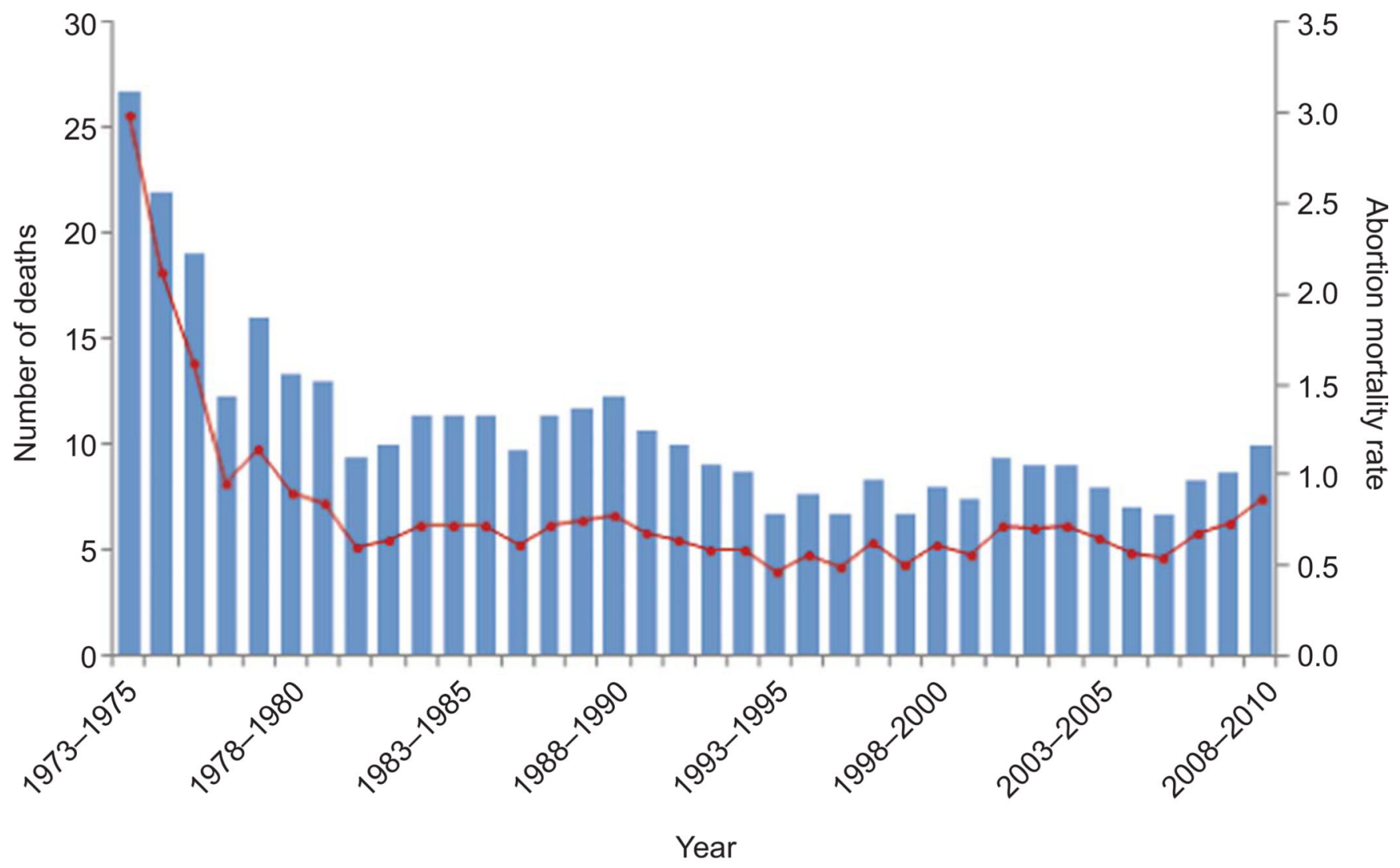

3-year moving average, number of legal induced abortion deaths

$\rightarrow$ 3-year moving average, abortion mortality rate per 100,000 legal induced abortions

Fig. 1.

Legal induced abortion mortality, number of deaths, and abortion mortality rates, United States, 1973-2010.

Zane. Abortion Mortality in the United States. Obstet Gynecol 2015. 


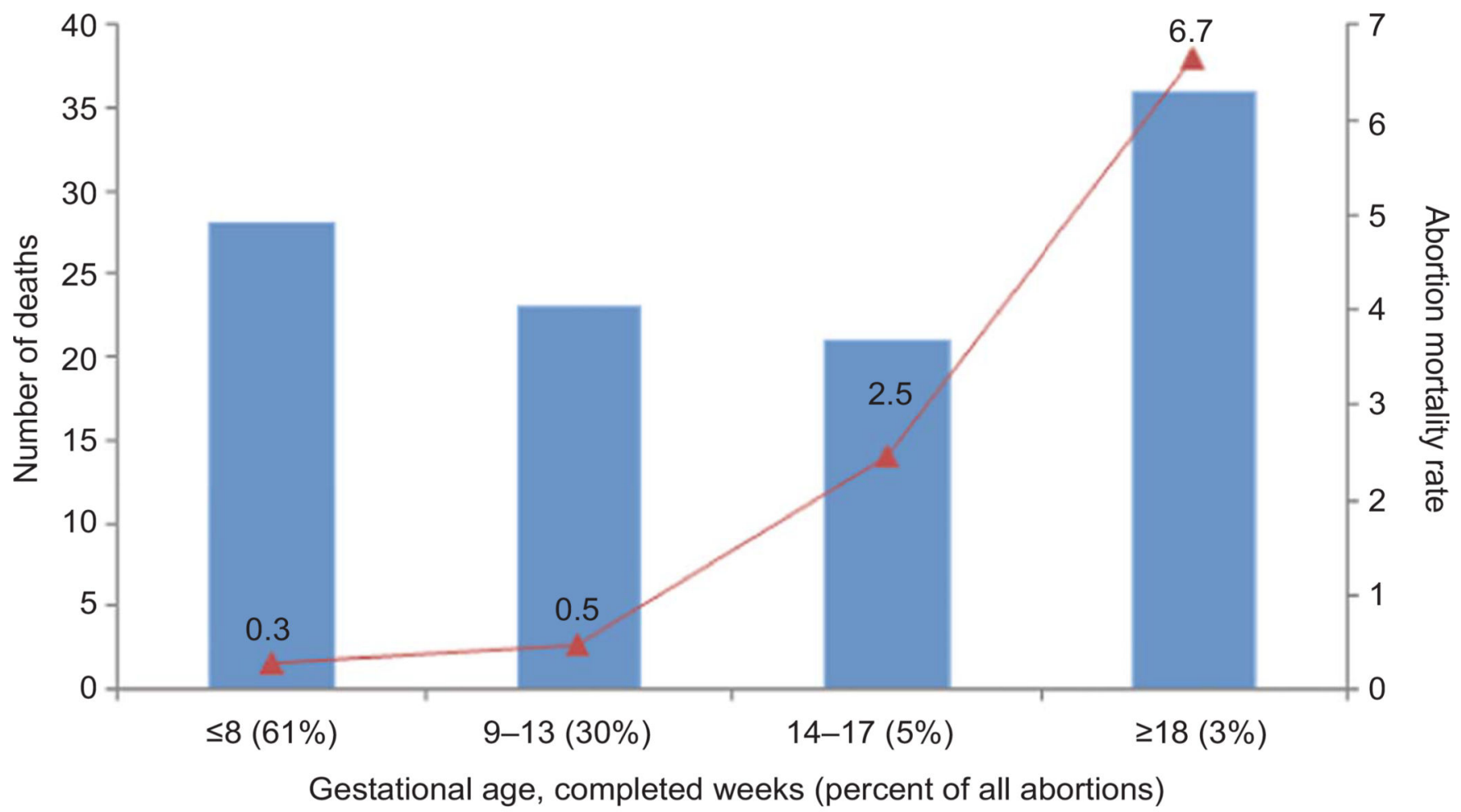

Number of legal induced abortion deaths

¿- Abortion mortality rate per 100,000 legal induced abortions

Fig. 2.

Distribution of legal induced abortion deaths and abortion mortality rates by gestational age, United States, 1998-2010.

Zane. Abortion Mortality in the United States. Obstet Gynecol 2015. 


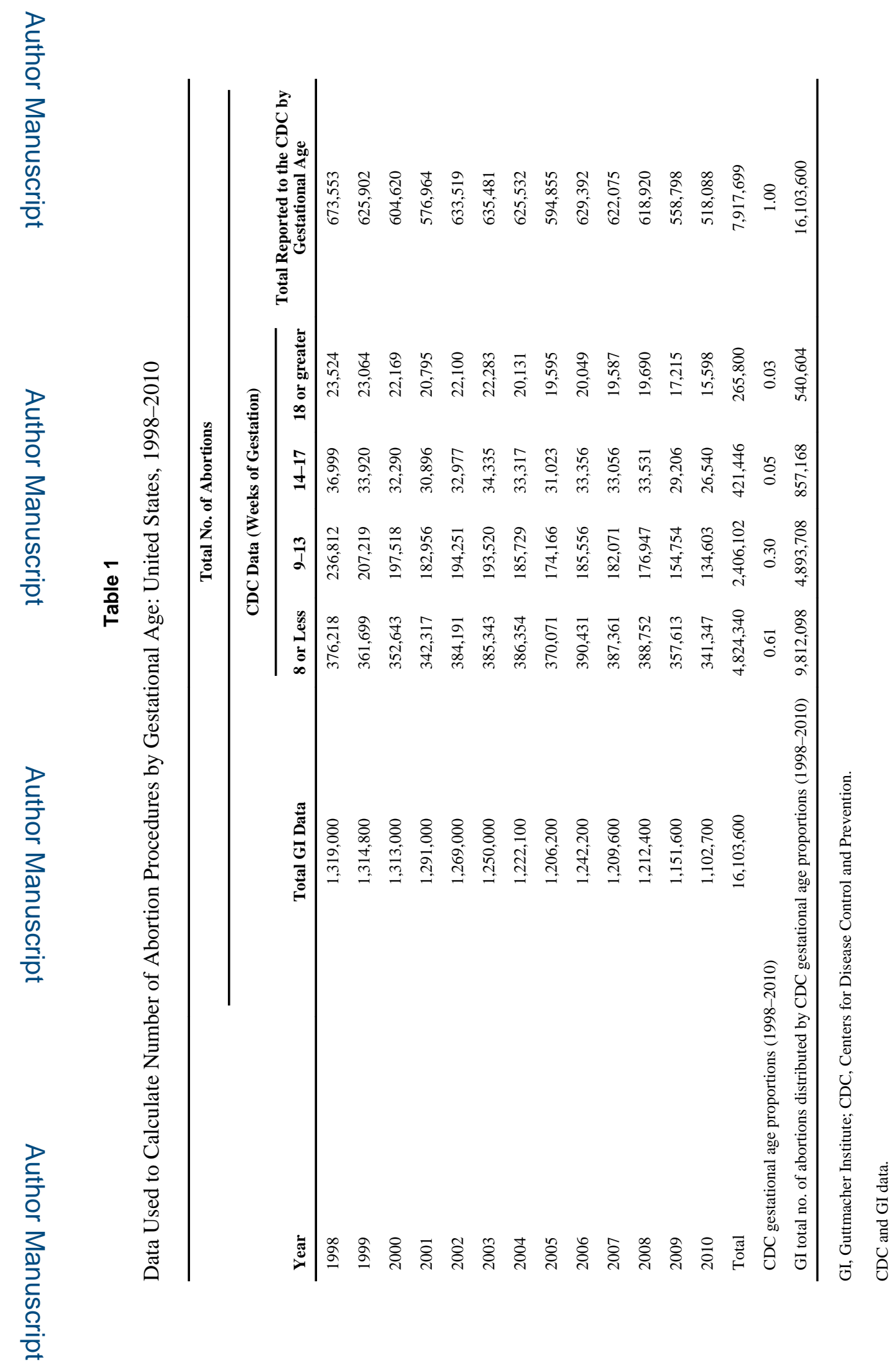

Obstet Gynecol. Author manuscript; available in PMC 2016 August 01. 


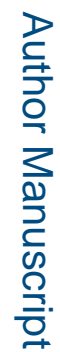

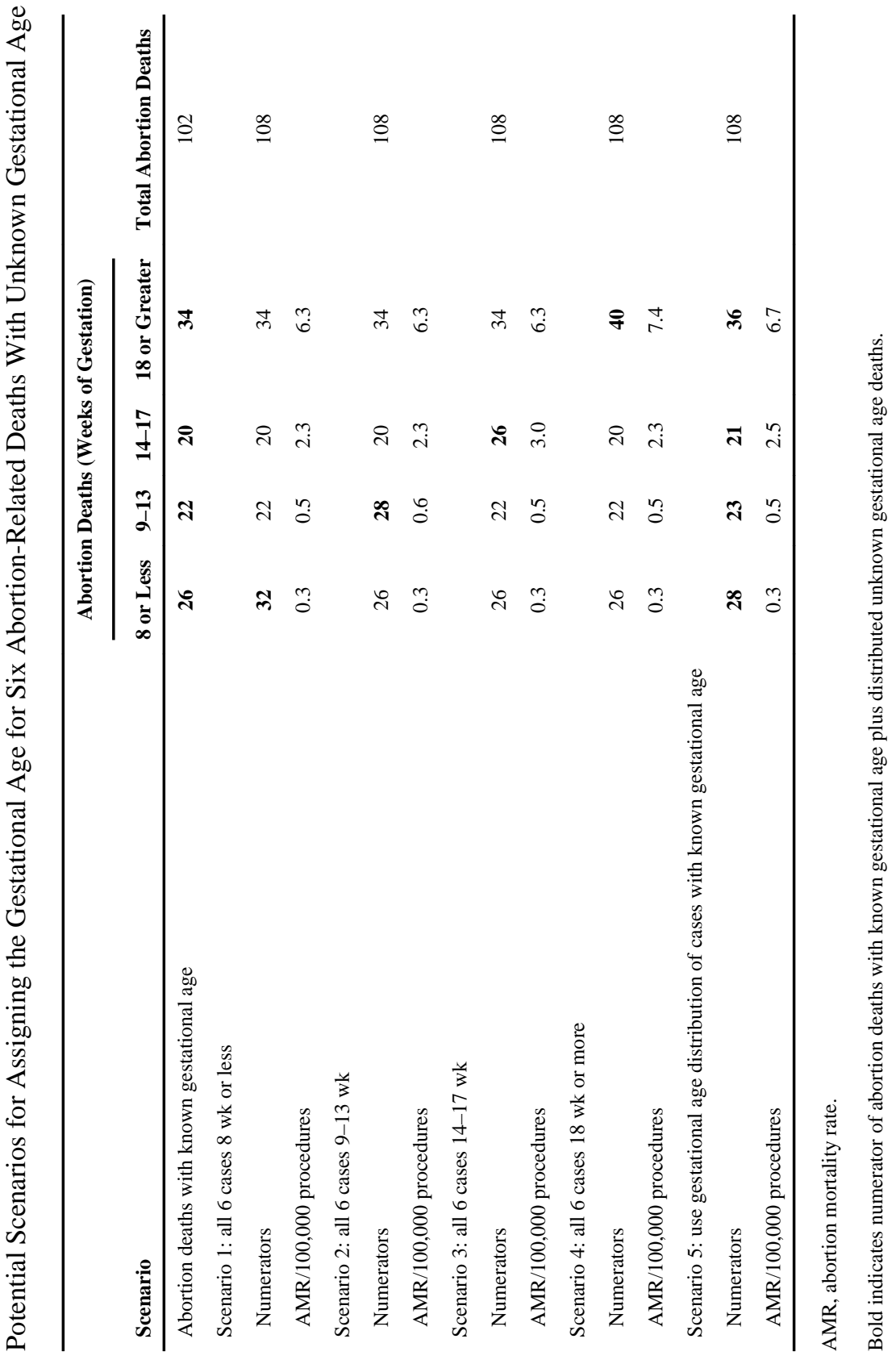

Obstet Gynecol. Author manuscript; available in PMC 2016 August 01. 
Table 3

Characteristics and Gestational Ages of Women With Abortion-Related Deaths: Pregnancy Mortality Surveillance System, United States, 1998-2010 (N=108)

\begin{tabular}{|c|c|}
\hline Sociodemographic Characteristics & Total \\
\hline \multicolumn{2}{|l|}{ Age (y) } \\
\hline 19 or younger & $13(12)$ \\
\hline $20-24$ & $30(28)$ \\
\hline $25-29$ & $25(23)$ \\
\hline $30-34$ & $23(21)$ \\
\hline 35 or older & $17(16)$ \\
\hline \multicolumn{2}{|l|}{ Race } \\
\hline White & $43(40)$ \\
\hline Black & $55(51)$ \\
\hline Other & $10(9)$ \\
\hline \multicolumn{2}{|l|}{ Hispanic origin } \\
\hline Hispanic & $20(19)$ \\
\hline Non-Hispanic & $84(78)$ \\
\hline Unknown & $4(4)$ \\
\hline \multicolumn{2}{|l|}{ Nativity } \\
\hline US-born & $82(76)$ \\
\hline Foreign-born & $26(24)$ \\
\hline \multicolumn{2}{|l|}{ Gravidity } \\
\hline 1 & $9(8)$ \\
\hline 2 & $17(16)$ \\
\hline 3 or more & $47(44)$ \\
\hline Unknown & $35(32)$ \\
\hline \multicolumn{2}{|l|}{ No. of previous live births } \\
\hline 0 & $8(7)$ \\
\hline 1 & $21(19)$ \\
\hline 2 & $16(15)$ \\
\hline 3 or more & $20(19)$ \\
\hline Unknown & $43(40)$ \\
\hline \multicolumn{2}{|l|}{ Education } \\
\hline 11 th grade or less & $23(21)$ \\
\hline 12th grade & $42(39)$ \\
\hline More than 12th grade & $34(32)$ \\
\hline Unknown & $9(8)$ \\
\hline \multicolumn{2}{|l|}{ Marital status } \\
\hline Never married & $69(64)$ \\
\hline Married or cohabiting & $28(26)$ \\
\hline Divorced or widowed & $10(9)$ \\
\hline Unknown & $1(1)$ \\
\hline
\end{tabular}




\begin{tabular}{|c|c|c|}
\hline & Sociodemographic Characteristics & Total \\
\hline & \multicolumn{2}{|l|}{ Gestational age (wk) } \\
\hline ट & 8 or less & $28(26)$ \\
\hline $\overrightarrow{\widehat{\sigma}}$ & $9-13$ & $23(21)$ \\
\hline$<$ & $14-17$ & 21 (19) \\
\hline & 18 or greater & $36(33)$ \\
\hline
\end{tabular}

Data are $\mathrm{n}(\%)$.

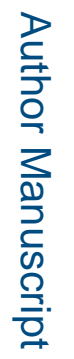


Table 4

Distribution of Causes of Death by Gestational Age and Type of Abortion Procedure: Pregnancy Mortality Surveillance System, United States, 1998-2010

\begin{tabular}{|c|c|c|c|}
\hline \multirow[b]{2}{*}{$\begin{array}{l}\text { Gestational } \\
\text { Age and Procedure }\end{array}$} & \multirow[b]{2}{*}{$\mathbf{n}$} & \multicolumn{2}{|c|}{ Cause of Death } \\
\hline & & Hemorrhage & Infection \\
\hline 13 wk of gestation or less & 48 & 5 & 19 \\
\hline No procedure ${ }^{*}$ & 1 & 0 & 0 \\
\hline Medical procedure ${ }^{\dagger}$ & 12 & 2 & 9 \\
\hline Suction curettage & 28 & 2 & 6 \\
\hline Unknown procedure & 7 & 1 & 4 \\
\hline More than $13 \mathrm{wk}$ of gestation & 54 & 17 & 17 \\
\hline No procedure ${ }^{*}$ & 4 & 0 & 3 \\
\hline Medical procedure ${ }^{\dagger}$ & 8 & 1 & 1 \\
\hline Dilation and evacuation & 39 & 16 & 12 \\
\hline Other procedure ${ }^{f}$ & 2 & 0 & 0 \\
\hline Unknown procedure & 1 & 0 & 1 \\
\hline Unknown gestational age & 6 & 0 & 1 \\
\hline Total, all gestational ages and all procedures & 108 & 22 & 37 \\
\hline
\end{tabular}

\begin{tabular}{|c|c|c|c|c|}
\hline \multicolumn{5}{|c|}{ Cause of Death } \\
\hline Embolism & Anesthesia Complications & Cardiovascular Diseases & Medical, Noncardiovascular Conditions & Unknown \\
\hline 5 & 14 & 1 & 3 & 1 \\
\hline 0 & 1 & 0 & 0 & 0 \\
\hline 0 & 0 & 1 & 0 & 0 \\
\hline 3 & 13 & 0 & 3 & 1 \\
\hline 2 & 0 & 0 & 0 & 0 \\
\hline 5 & 7 & 3 & 4 & 1 \\
\hline 0 & 1 & 0 & 0 & 0 \\
\hline 2 & 0 & 2 & 2 & 0 \\
\hline 2 & 6 & 1 & 1 & 1 \\
\hline 1 & 0 & 0 & 1 & 0 \\
\hline 0 & 0 & 0 & 0 & 0 \\
\hline 2 & 1 & 1 & 1 & 0 \\
\hline 12 & 22 & 5 & 8 & 2 \\
\hline
\end{tabular}

Data are n.

* No procedure: Laminaria placed or anesthesia administered but planned abortion procedure never occurred.

${ }^{\dagger}$ Medical procedure: administration of medication(s), typically mifepristone followed by misoprostol at 8 weeks of gestation or less and vaginal prostaglandins at more than 8 weeks of gestation.

* Other procedures: hysterotomy and intrauterine instillation. 